\section{Obstetric fistula in Assam, India: a neglected cause of maternal morbidities and mortality}

\author{
Suresh Jungari, Bal Govind Chauhan \\ International Institute for Population \\ Sciences, Mumbai, Maharashtra, India
}

\begin{abstract}
Each year between 50,000 to 100,000 women worldwide are affected by obstetric fistula, a hole in the birth canal. Obstetric fistula is one of the major cause for maternal morbidities and mortality and it has been successfully eradicated in developed nations. Women who experience obstetric fistula suffer constant incontinence, shame, and social segregation. Obstetric fistula is prevalent in African and Asian countries, including India. In India, data has been collected in a large scale survey of district level household survey regarding obstetric fistula and its causes. In this study, efforts are endeavoured to understand the prevalence and causes of obstetric fistula in Assam state, India, where prevalence of obstetric fistula is very high (4.5\%). Chi-square test was applied to determine the affecting factors of obstetric fistula. Results showing the socioeconomic status, education, place of residence and age group are important determinants in variation of fistula prevalence among women.
\end{abstract}

\section{Introduction}

Obstetric fistula is a hole or tear in the tissue wall between the vagina and the bladder or rectum, or a hole between them both that results in incontinence of urine. Obstetric fistula is the most devastating of all pregnancyrelated disabilities. It is an injury of childbirth that has been relatively neglected, and is usually caused by several days of obstructed labour. It is estimated that more than 2 million young women live with untreated obstetric fistula in Asia and sub-Saharan Africa. ${ }^{1}$ Obstetric fistula cases are prevented by taking adequate care during pregnancy. ${ }^{2}$ Commonest fistulas are genitourinary, rectovaginal and both genitourinary and rectovaginal. ${ }^{3}$ Obstetric fistula problems are still prevalent in the underdeveloped world, but developed nations do not have fistula cases because of the availability of high quality emergency obstetric services.

Prolonged obstructed labour during pregnancy and lacking availability of healthcare services on time are major causes for obstetric fistula formation. In obstructed labour the soft tissues of the pregnant woman's vagina, bladder, and rectum are compressed between the fetal head and the maternal pelvic bones by the contractions of the uterus. As the fetal head is forced tighter and tighter into the pelvis, the blood supply to the mother's soft tissues is progressively constricted, and ultimately it is completely shut off. ${ }^{4}$ In almost all cases of fistula, the baby dies. An obstetric fistula leads to high rates of infant, child and maternal mortality.

Sexual assault, including rape and forced insertion of objects into a woman's vagina leads to fistula. A fistula resulting from sexual violence is one example of a traumatic gynaecologic fistula., ${ }^{5,6}$ Traumatic fistulas are rare compared to obstetric fistulas. Fistulas indirectly related to sexual violence are likely to be more common than those directly related ${ }^{7}$ and sexual violence can lead to more pregnancy complication and fistulas in India. ${ }^{8}$

Obstetric fistula is one of the neglected causes of maternal mortality in the developing world, including India. It has several health consequences on women reproductive health and it is considered as a major public health threat. ${ }^{9}$ Maternal morbidity affects women, their families, communities and societies and country at large. ${ }^{10}$ Moreover, untreated obstetric fistula can lead to secondary infertility. Poverty, illiteracy, traditional practices during childbirth and pregnancy in young ages are the major social causes of obstetric fistula in developing countries including India.

The social consequence of obstetric fistula is pathetic: women are blamed, they are excluded from mainstream and under the isolation they may not receive treatment in time lives with longer duration. Due to continue urine leaking women feel ashamed, and in some cases they receive violence from intimate partner. More than $50 \%$ of obstetric fistula affected women are divorced by husbands in India. ${ }^{11,12}$ Another social consequence of obstetric fistula is the suicide of affected women: a study in Bangladesh and Ethiopia found that $97 \%$ of women with obstetric fistula were screened positive for potential mental health dysfunction. This shows how women with obstetric fistula are at high risk of mental health problems, ${ }^{13,14}$ and are predisposed to high levels of depression and suicidal ideations. $^{15}$

Data on obstetric fistula is scarce: any population-based data for prevalence of obstetric fistulas is not available and research on causes and consequences of obstetric fistula is needed for further exploring the issue. Reliable data and research on this maternal morbidity burden is lacking ${ }^{16-18}$ due to the stigma related to this condition. Fistula untreated cases may not be reported and underestimation of fistula cases is another issue of concern.
Correspondence: Suresh Jungari, International Institute for Population Sciences, Govand Station Road, Mumbai, 400088 Maharashtra, India.

Tel: +91.22 .2556 .3489$

E-mail: sureshjungariiips@gmail.com

Key words: obstetric fistula, maternal mortality, district level household survey, institutional delivery.

Received for publication: 5 August 2014

Accepted for publication: 19 August 2014.

This work is licensed under a Creative Commons Attribution 3.0 License (by-nc 3.0).

(O)Copyright S. Jungari and B. Govind Chauhan, 2015 Licensee PAGEPress, Italy

Healthcare in Low-resource Settings 2015; 3:4663 doi:10.4081/hls.2015.4663

Research in India found that small obstetric fistulas can be repaired and cured with layered closure and complicated fistulas can be repaired with tissue interposition or tissue graft, ${ }^{19}$ but one of the complication after the repair of the obstetric fistula is that $10-30 \%$ of women is still left with urinary incontinence even if the fistula is closed. ${ }^{20,21}$ The majority of the studies are undertaken in a hospital set or are trial-controlled studies and focus on medical aspects; very few studies are attempted to understand the sociological consequences of obstetric fistula.

\section{Maternal health situation in Assam, India}

Assam state belongs to the Empowered Action Group States, selected by the government on the basis of socio-economic indicators. Demographic and health indicators reveal that Assam state is poorer than other states. According to the sample registration system report 2011, the maternal mortality ratio is 390 , which is higher than total Indian 212 (2007-09). Despite government efforts to reduce maternal mortality burden through National Rural Health Mission schemes, e.g. Janani Surksha Yojan, no real improvement has been observed. Utilization of maternal health services in the state is minimal as compared to other states and India. Any antenatal care is $57 \%$, which is considered to be very poor: its utilization is much important because possible pregnancy complications can be ascertained in early stage of pregnancy and it can be useful in avoiding obstetric emergences. Institutional deliveries of the state represent only $23 \%$ and in rural areas they are reduced to $18 \%$, which is a great area of concern to avoid pregnancy-related complications..$^{22}$ According to the District Level 
Household Survey (DLHS)-3, ${ }^{23}$ prevalence of obstetric fistulas in Assam is unacceptably high (4.5\%) compared to all other states, and national prevalence of obstetric fistula is $1.2 \%$, which is another bad indicator for higher maternal mortality and morbidities. DLHS-3 represents the very first time nationwide data on the prevalence of obstetric fistula and its determinants has been collected.

All this considered, this study intends to understand the prevalence and the determinants of higher percentage obstetric fistulas in Assam state, India.

Table 1. Obstetric fistula prevalence in Indian states.

\begin{tabular}{lcc} 
States & \multicolumn{2}{c}{ Obstetric fistula } \\
& n & $\%$ \\
\hline Jammu and Kashmir & 15,161 & 3.0 \\
Himachal Pradesh & 10,015 & 1.5 \\
\hline Punjab & 20,889 & 0.0 \\
Chandigarh & 848 & 0.0 \\
\hline Uttarakhand & 12,636 & 3.1 \\
Haryana & 21,411 & 0.2 \\
\hline Delhi & 8096 & 0.8 \\
Rajasthan & 40,222 & 0.4 \\
\hline Uttar Pradesh & 86,029 & 1.6 \\
Bihar & 45,800 & 1.5 \\
\hline Sikkim & 4399 & 1.5 \\
Arunachal Pradesh & 15,074 & 0.4 \\
\hline Manipur & 9263 & 1.4 \\
Mizoram & 7846 & 0.3 \\
\hline Tripura & 4166 & 0.2 \\
Meghalaya & 6941 & 0.7 \\
\hline Assam & 30,241 & 4.5 \\
West Bengal & 21,863 & 0.8 \\
\hline Jharkhand & 26,828 & 2.5 \\
Orissa & 27,842 & 0.5 \\
\hline Chhattisgarh & 18,128 & 0.3 \\
\hline Madhya Pradesh & 46,148 & 3.4 \\
\hline Gujarat & 24,162 & 2.7 \\
\hline Daman and Diu & 1943 & 1.3 \\
\hline Dadra and Nagarhaveli & 921 & 4.1 \\
\hline Maharashtra & 34,900 & 1.5 \\
\hline Andhra Pradesh & 21,716 & 1.8 \\
Karnataka & 27,779 & 1.0 \\
\hline Goa & 1452 & 2.1 \\
\hline Lakshadweep & 1363 & 0.4 \\
\hline Kerala & 12,359 & 0.6 \\
\hline Pondicherry & & \\
\hline
\end{tabular}

\section{Materials and Methods}

\section{Data source}

This study used data from most recent DLHS, i.e. DLHS-3 (2007-08), ${ }^{23}$ which is one of the largest demographic and health surveys ever carried out in India, with a sample size of about 700,000 households covering all the districts of the country. In 1997, the Ministry of Health and Family Welfare, Government of India, started to provide district level estimates on health indicators to assist policy makers and program administrators in decentralized planning, monitoring and evaluation. The present DLHS is the third in the series preceded by DLHS-1 in 1998-99 and DLHS-2 in 2002-

04. DLHS-3 interviewed ever-married women (age 15-49) and never married women (age 15-24). DLHS-3 adopts a multi-stage stratified probability proportional to size sampling design. In DLHS-3, a separate module of obstetric fistula consisting of five questions was canvassed to all ever-married women to gather information on fistula status.

\section{Methods}

Information about women reproductive morbidities has been collected through questionnaires to understand the fistula prevalence. Women who said yes to the question Do you have a problem of urine incontinence were considered as fistula cases. Following this, one more question was asked, i.e. When the problem started?, to understand the causes of obstetric fistula, which are, hospital delivery, pelvic surgery, sexual violence or other. Cross tabulation and chi-square test were applied to understand fistula prevalence and causes.

\section{Study variables}

Current age of mothers, education, place of residence, parity, birth order, religion, caste, wealth quintile, induced abortion were the study variables. Obstetric fistula has been considered as an outcome variable in the study.

Table 2. Chi-square analysis of obstetric fistula prevalence in Assam state, India.

\begin{tabular}{|c|c|c|}
\hline Background characteristics & n & $\%$ \\
\hline $\begin{array}{l}\text { Current age of respondent (years) } \\
\quad<20 \\
\quad 20-24 \\
25-29 \\
30-34\end{array}$ & $\begin{array}{l}1454 \\
4674 \\
6449 \\
5717\end{array}$ & $\begin{array}{c}(4.580) \\
3.5 \\
4.8 \\
4.6 \\
4.3\end{array}$ \\
\hline $35-49$ & 11,946 & 4.5 \\
\hline $\begin{array}{l}\text { Parity } \\
\quad \begin{array}{l}1 \\
2-3 \\
\geq 4\end{array}\end{array}$ & $\begin{array}{l}3679 \\
4147 \\
2145 \\
\end{array}$ & $\begin{array}{c}(0.402) \\
4.8 \\
4.7 \\
4.5\end{array}$ \\
\hline $\begin{array}{l}\text { Place of residence } \\
\text { Rural } \\
\text { Urban }\end{array}$ & $\begin{array}{c}26,626 \\
3615\end{array}$ & $\begin{array}{c}(18.485)^{* * *} \\
4.7 \\
3.1\end{array}$ \\
\hline $\begin{array}{l}\text { Educational level (years) } \\
\text { Non literate } \\
\quad<5 \\
5-9 \\
\geq 10\end{array}$ & $\begin{array}{c}30 \\
4202 \\
10,621 \\
5179\end{array}$ & $\begin{array}{l}(9.535)^{* *} \\
3.3 \\
4.6 \\
4.4 \\
3.5\end{array}$ \\
\hline $\begin{array}{l}\text { Religion } \\
\text { Hindu } \\
\text { Muslim } \\
\text { Other }\end{array}$ & $\begin{array}{c}20,746 \\
8137 \\
1357\end{array}$ & $\begin{array}{c}(20.819)^{* * *} \\
4.7 \\
3.6 \\
5.7\end{array}$ \\
\hline $\begin{array}{l}\text { Cast/tribe } \\
\text { Schedule cast } \\
\text { Schedule tribe } \\
\text { Other }\end{array}$ & $\begin{array}{c}3290 \\
7316 \\
19,635 \\
\end{array}$ & $\begin{array}{c}(9.415)^{* * *} \\
3.7 \\
5.0 \\
4.4 \\
\end{array}$ \\
\hline $\begin{array}{l}\text { Wealth index } \\
\text { Poor } \\
\text { Middle } \\
\text { Rich }\end{array}$ & $\begin{array}{c}11,846 \\
8617 \\
9776\end{array}$ & $\begin{array}{c}(20.270)^{* * *} \\
4.9 \\
4.7 \\
3.7\end{array}$ \\
\hline $\begin{array}{l}\text { Induced abortion } \\
\text { No } \\
\text { Yes }\end{array}$ & $\begin{array}{c}28,366 \\
1871\end{array}$ & $\begin{array}{c}(51.051)^{* * *} \\
4.3 \\
7.8\end{array}$ \\
\hline Total & 30,241 & 4.5 \\
\hline
\end{tabular}

Values in brackets represent chi-square test at 0.05 level of significance. 


\section{Results}

Table 1 shows the prevalence of obstetric fistula among all states in India. Assam state has higher percent of fistula (4.5\%), followed by Madya Pradesh (3.4\%) and Uttarakhand (3.2\%). Those states lacking behind in maternal health indicators have higher percent of obstetric fistula prevalence. Kerla, Tamilnadu, Hariyana, and Punjab have the least prevalence of obstetric fistula cases. Table 2 shows the weighted percentage of women who experienced obstetric fistula by selecting their background characteristics. Overall, $4.5 \%$ of women experienced obstetric fistula. of $<20$ year-old women, $3.5 \%$ experienced any type of symptom of obstetric fistula, while older women (20-24-year-old) with obstetric fistula were $4.8 \%$. The percentage of obstetric fistula was $4.8,4.7$ and 4.5 respectively, with parity 1 , $2-3$ and $\geq 4$, respectively. Of ever married women living in rural areas, $4.7 \%$ experienced obstetric fistula compared to city dwellers (3.1\%). The percentage of obstetric fistula was 3.3 among women with no education, and 3.5 for those with 10 or more years of education. Muslim women experiencing obstetric fistula were $3.6 \%$, while those belonging to other religious groups and experiencing the disease were $5.7 \%$. Women belonging to schedule tribes, living in a poor economic status, and experiencing induced abortion more likely experienced obstetric fistula (5.0, 4.9, and $7.8 \%$, respectively). Women who ever experienced obstetric fistula were asked about the causes of their diesase. There seem to be four main causes (Table 3 ): about $75.2 \%$ of women have experience of obstetric fistula after hospital delivery, $7.2 \%$ after surgery, $14.4 \%$ as a result of sexual violence (considered as a traumatic gynaecologic fistula), and only $3.3 \%$ due to other causes.

\section{Discussion}

Reducing child mortality and improving maternal health represent the fourth and fifth millennium developmental goals, respectively.

Table 3. Causes of obstetric fistula in Assam, India.

\begin{tabular}{lcc} 
Causes & n & $\%$ \\
Hospital delivery & 1016 & 75.2 \\
Pelvic surgery & 97 & 7.2 \\
\hline Sexual assault & 194 & 14.4 \\
Other & 44 & 3.3 \\
\hline Total & 1351 & 100.0 \\
\hline
\end{tabular}

To achieve these goals, all levels of improvement in maternal health situation are required and in India improvements in maternal indicators in the so-called Empowered Action Group States is crucial. Obstetric fistula is one of the major causes of maternal morbidities and mortality. The present study used the most recent data of DLHS-3 (2007-8) which is the first of its kind to collect information on obstetric fistula. Study results clearly show the alarming picture of Assam state in India. The consequences of higher prevalence are long lasting.

Both medical and social consequences of obstetric fistula are vast, fistula-affected women often face the isolation and frustration which can lead to further psychological disorders. In India many husbands obtain divorce from fistula-affected women. The study found daunting results: $14.4 \%$ of fistula cases are due to sexual violence by husbands (traumatic gynaecologic fistula) and many similar cases are not yet reported nor documented. Morevoer, a number of barriers delay women's access to traumatic fistula services, like higher financial costs and lack of awareness about available services. Prevention of fistula is important to reduce the burden of maternal morbidities and mortality and it could be attained by providing appropriate maternal health services and emergency obstetric care. To overcome the burden of fistula, programmatic approaches integrated with other maternal health services are urgently needed.

\section{Limitations of the study}

Information has been collected on the basis of symptoms of obstetric fistula, therefore it does not provide small details. The study results may be then considered only as tentatively providing the prevalence of the disease.

\section{Conclusions}

Higher and unacceptable prevalence of obstetric fistulas in Assam state is disturbing news for healthcare providers, health system managers, policy makers and especially for those who are pregnant and exposed to any form of violence. The major reasons for fistula are obstetric labour during child birth and sexual violence by husbands. Women in rural areas are at greater risk to be affected by fistula, as the availability of emergency obstetric care in rural areas is very minimal. Also, illiterate women are more likely to affect fistula than educated ones. International to local efforts are needed to solve this problem, overall by informing women on available antenatal services and identifying possible pregnancy complications.

\section{References}

1. WHO. Mental health aspects of women's reproductive health: a global review of the literature. Geneva, Switzerland: World Health Organization; 2009.

2. McCord C, Premkumar R, Arole S, Arole R. Efficient and effective emergency obstetric care in a rural Indian community where most deliveries are at home. Int $\mathbf{J}$ Gynaecol Obstet 2001;75:297-307.

3. Singh S, Chandhiok N, Dhillon BS. Obstetric fistula in India: current scenario. Int Urogynecol J 2009;20:1403-5.

4. Wall LL. Obstetric vesicovaginal fistula as an international public-health problem. Lancet 2006;368:1201-9.

5. Arrowsmith SD, Ruminjo J, Landry EG. Current practices in treatment of female genital fistula: a cross sectional study. BMC Pregnancy Childbirth 2010;10:73.

6. ACQUIRE Project. Traumatic gynaecological fistula: a consequence of sexual violence in conflict settings. A report of a meeting held in Addis Ababa, Ethiopia. New York, NY: ACQUIRE Project/Engender Health; 2006.

7. Onsrud M, Sjøveian S, Luhiriri R, Mukwege D. Sexual violence-related fistulas in the Democratic Republic of Congo. Int J Gynaecol Obstet 2008;103:265-9.

8. WHO. Understanding and addressing violence against women: health consequences. Geneva, Switzerland: World Health Organization; 2012.

9. Medina M, Roedee G, Decosas J, et al. Thematic evaluation of the national programmes and UNFPA experience in the campaign to end fistula: assessment of national programmes. Final synthesis report. New York, NY: UNFPA; 2010.

10. National Research Council. The consequences of maternal morbidity and maternal mortality: report of a workshop. Washington, DC: National Academy Press; 2000.

11. Wall LL, Arrowsmith SD, Briggs ND, et al. Urinary incontinence in the developing world: the obstetric fistula. J Obstet Gynaecol 2003;23:439-40.

12. Ahmed S, Holtz SA. Social and economic consequences of obstetric fistula: life changed forever? Int $\mathrm{J}$ Gynaecol Obstet 2007;99:10-5.

13. Goh JT, Sloane KM, Krause HG, et al. Mental health screening in women with genital tract fistulae. Int $\mathrm{J}$ Gynaecol Obstet 2005;112:1328-30.

14. Browning A, Fentahun W, Goh JTW. The impact of surgical treatment on the mental health of women with obstetric fistula. Int J Gynaecol Obstet 2007;114:1439-41.

15. Weston K, Mutiso S, Mwangi JW, et al. 
Depression among women with obstetric fistula in Kenya. Int $\mathbf{J}$ Gynaecol Obstet 2011;115:31-3.

16. Zheng AX, Anderson FW. Obstetric fistula in low-income countries. Int $\mathrm{J}$ Gynaecol Obstet 2009;104:85-9.

17. Hardee K, Gay J, Blanc AK. Maternal morbidity: neglected dimension of safe motherhood in the developing world. Global Public Health 2012;7:603-17.

18. Stanton C, Holtz SA, Ahmed S. Challenges in measuring obstetric fistula. Int $\mathrm{J}$ Gynaecol Obstet 2007;99:4-9.

19. Goyal NK, Dwivedi US, Vyas N, et al. A decade's experience with vesicovaginal fistula in India. Int Urogynecol $\mathrm{J}$ 2007;18:39-42.

20. Kelly MJ, Kwast BE. Epidemiologic study of vesicovaginal fistulas in Ethiopia. Int Urogynecol J 1993;4:278-81.

21. Browning A. Prevention of residual urinary incontinence following successful repair of obstetric vesico-vaginal fistula using a fibro-muscular sling. Int $\mathrm{J}$ Gynaecol Obstet 2004;111:357-61.

22. IIPS. National family health survey (NFHS), 2005-06. Mumbai, India: International Institute for Population Sciences; 2007.

23. IIPS. District level household and facility survey (DLHS-3), 2007-08. Mumbai, India: International Institute for Population Sciences; 2010. 